\title{
Outdoor air pollution and the burden of childhood asthma across Europe
}

\author{
Haneen Khreis ${ }^{1,2,3,4,9}$, Marta Cirach ${ }^{2,3,4}$, Natalie Mueller ${ }^{2,3,4}$, Kees de Hoogh ${ }^{5,6}$, \\ Gerard Hoek $^{7}$, Mark J. Nieuwenhuijsen ${ }^{2,3,4}$ and David Rojas-Rueda (1) 2,3,8,9
}

Affiliations: ${ }^{1}$ Center for Advancing Research in Transportation Emissions, Energy, and Health (CARTEEH), Texas A\&M Transportation Institute (TTI), College Station, TX, USA. ${ }^{2}$ ISGlobal, Centre for Research in Environmental Epidemiology (CREAL), Barcelona, Spain. ${ }^{3}$ Universitat Pompeu Fabra (UPF), Barcelona, Spain. ${ }^{4}$ CIBER Epidemiologia y Salud Publica (CIBERESP), Madrid, Spain. ${ }^{5}$ Swiss Tropical and Public Health Institute, Basel, Switzerland. ${ }^{6}$ University of Basel, Basel, Switzerland. ${ }^{7}$ Division of Environmental Epidemiology, Institute for Risk Assessment Sciences, Utrecht University, Utrecht, The Netherlands. ${ }^{8}$ Environmental and Radiological Health Sciences, Colorado State University, Fort Collins, CO, USA. ${ }^{9}$ These authors are joint lead authors of the study.

Correspondence: Haneen Khreis, Center for Advancing Research in Transportation Emissions, Energy, and Health (CARTEEH), Texas A\&M Transportation Institute (TTI), 2929 Research Parkway, 3135 TAMU, College Station, TX 77843-3135, USA. E-mail: h-khreisdtti.tamu.edu

@ERSpublications

A significant proportion (up to 33\%) of incident childhood asthma cases across Europe may be attributable to outdoor air pollution. These cases are largely preventable, underlying an urgent need to reduce children's exposure to $\mathrm{NO}_{2}, \mathbf{P M}_{2.5}$ and black carbon. http://bit.ly/36Fe $5 \mathrm{KN}$

Cite this article as: Khreis $\mathrm{H}$, Cirach $\mathrm{M}$, Mueller $\mathrm{N}$, et al. Outdoor air pollution and the burden of childhood asthma across Europe. Eur Respir J 2019; 54: 1802194 [https://doi.org/10.1183/13993003.021942018].

\section{ABSTRACT}

Background: Emerging evidence suggests that air pollution may contribute to childhood asthma development. We estimated the burden of incident childhood asthma that may be attributable to outdoor nitrogen dioxide $\left(\mathrm{NO}_{2}\right)$, particulate matter $\leqslant 2.5 \mu \mathrm{m}$ in diameter $\left(\mathrm{PM}_{2.5}\right)$ and black carbon $(\mathrm{BC})$ in Europe. Methods: We combined country-level childhood incidence rates and pooled exposure-response functions with childhood (age 1-14 years) population counts, and exposure estimates at $15403861 \mathrm{~km} \times 1 \mathrm{~km}$ cells, across 18 European countries and 63442419 children. Annual average pollutant concentrations were obtained from a validated and harmonised European land-use regression model. We investigated two exposure reduction scenarios. For the first, we used recommended annual World Health Organization (WHO) air quality guideline values. For the second, we used the minimum air pollution levels recorded across 41 studies in the underlying meta-analysis.

Results: $\mathrm{NO}_{2}$ ranged from 1.4 to $70.0 \mu \mathrm{g} \cdot \mathrm{m}^{-3}$, with a mean of $11.8 \mu \mathrm{g} \cdot \mathrm{m}^{-3}$. $\mathrm{PM}_{2.5}$ ranged from 2.0 to $41.1 \mu \mathrm{g} \cdot \mathrm{m}^{-3}$, with a mean of $11.6 \mu \mathrm{g} \cdot \mathrm{m}^{-3}$. BC ranged from 0.003 to $3.7 \times 10^{-5} \mathrm{~m}^{-1}$, with a mean of $1.0 \times 10^{-5} \mathrm{~m}^{-1}$. Compliance with the $\mathrm{NO}_{2}$ and $\mathrm{PM}_{2.5}$ WHO guidelines was estimated to prevent 2434 $(0.4 \%)$ and $66567(11 \%)$ incident cases, respectively. Meeting the minimum air pollution levels for $\mathrm{NO}_{2}$ $\left(1.5 \mu \mathrm{g} \cdot \mathrm{m}^{-3}\right), \mathrm{PM}_{2.5}\left(0.4 \mu \mathrm{g} \cdot \mathrm{m}^{-3}\right)$ and BC $\left(0.4 \times 10^{-5} \mathrm{~m}^{-1}\right)$ was estimated to prevent 135257 (23\%), 191883 (33\%) and 89191 (15\%) incident cases, respectively.

Conclusions: A significant proportion of childhood asthma cases may be attributable to outdoor air pollution and these cases could be prevented. Our estimates underline an urgent need to reduce children's exposure to air pollution. 


\section{Introduction}

Asthma is a chronic disorder of the airways affecting more than 334 million individuals worldwide [1]. Asthma is often cited as the most common chronic disease in childhood [2-4]. The social burden of childhood asthma is considerable. It manifests in the disruption of the child's life, reduced physical abilities due to symptoms or attacks, the burden posed on the child's caregiver, and direct healthcare costs arising from consultations in primary and secondary care, hospital admissions, and treatment costs [5].

The most recent systematic review and meta-analysis established statistically significant associations between long-term exposure to outdoor air pollution, specifically black carbon (BC), nitrogen dioxide $\left(\mathrm{NO}_{2}\right)$, particulate matter $\leqslant 2.5 \mu \mathrm{m}$ in diameter $\left(\mathrm{PM}_{2.5}\right)$ and particulate matter $\leqslant 10 \mu \mathrm{m}$ in diameter $\left(\mathrm{PM}_{10}\right)$, and the development of childhood asthma from birth to 18 years old [6]. In urban areas, these pollutants are often traffic related, to varying extents, with $\mathrm{NO}_{2}$ and $\mathrm{BC}$ being better markers of traffic sources than particulate matter [6-9]. In line with these findings, more recent primary studies also showed that exposures to outdoor air pollution and specific traffic markers were associated with asthma development in children [10-13]. Supporting these epidemiological observations, the available toxicological and clinical evidence suggests that there are documented biological mechanisms by which air pollution could plausibly induce new childhood asthma and plausibly contribute to the diagnosis of asthma in a clinical setting $[14,15]$.

Despite this emerging evidence, which has fundamental implications for estimating the burden of disease attributable to outdoor air pollution beyond mortality end-points [16], to date little work has been undertaken to estimate the burden of childhood asthma attributable to outdoor air pollution. Four studies, from the same research group, quantified the number of prevalent asthma cases attributable to traffic-related air pollution (TRAP) as characterised by proximity to major roadways [16-19]. Three of these studies were conducted in California in the USA, in Long Beach, Riverside and Los Angeles counties $[16,18,19]$, while the fourth study was conducted across 10 European cities: Barcelona, Bilbao, Brussels, Granada, Ljubljana, Rome, Seville, Stockholm, Valencia and Vienna [17]. All four studies estimated the impact of proximity to major roadways (as the TRAP exposure surrogate) on asthma prevalence in children up to 18 years old and suggested that $6-14 \%$ of prevalent asthma cases may be attributable to proximity to major roadways. Two more recent analyses were set in Bradford in the UK. The first suggested that between $7 \%$ and $12 \%$ of annual incident childhood asthma cases may be attributable to traffic-related $\mathrm{NO}_{2}$ and nitrogen oxides $\left(\mathrm{NO}_{x}\right)$ exposures, as characterised by Gaussian dispersion models [20]. The percentage of annual incident childhood asthma cases attributable to $\mathrm{NO}_{2}$ and $\mathrm{NO}_{x}$ exposures from all sources (including industry, point sources, heating, aircraft, rail and regional sources) was $22 \%$ and $35 \%$, respectively [20]. The second study in Bradford suggested that $7 \%, 11 \%$ and $12 \%$ of annual incident childhood asthma cases may be attributable to traffic-related $\mathrm{PM}_{2.5}, \mathrm{PM}_{10}$ and $\mathrm{BC}\left(\mathrm{PM}_{2.5}\right.$ absorbance), respectively, as estimated by land-use regression (LUR) models [21]. The percentage of annual incident childhood asthma cases attributable to $\mathrm{PM}_{2.5}, \mathrm{PM}_{10}$ and $\mathrm{BC}$ exposures from all sources was $27 \%, 33 \%$ and $15 \%$, respectively [21].

Thus, the geographical coverage of previous studies was limited and the broadest coverage was reported in the paper by PEREZ et al. [17], which covered 10 cities in six European countries but used proximity to major roadways as the exposure metric. Furthermore, all previous studies, except for KHREIs et al. [20] and the follow-up work in KHREIS et al. [21, ], were concerned with asthma prevalence, rather than asthma incidence/development. As such, those studies did not take into account the latest evidence associating air pollution with childhood asthma development and do not give any indication of how many cases may be preventable by reducing air pollution exposures.

In this article, we take into account recent findings showing that outdoor air pollution exposures, specifically TRAP, are associated with the development of childhood asthma and we significantly expand the geographical coverage of previous analyses. We aim to estimate the annual number of incident childhood asthma cases that may be attributable to outdoor air pollution, across 18 European countries and 63442419 children, exploiting recently developed and harmonised European models of outdoor air pollution concentrations. In line with previous published works, we also assume that the same risk estimates sourced from the most recent meta-analysis can be applied to both traffic-related and generic outdoor air pollution [6], keeping in mind that intra-urban variations of air pollution, specifically BC and $\mathrm{NO}_{2}$, are mainly dominated by traffic sources [22], and that $\mathrm{NO}_{2}$ is likely acting as a surrogate for the traffic mixture.

\section{Methods}

\section{Study area and time-points}

The analyses presented in this paper covered 18 European countries: 16 from the European Union (EU) (Austria, Belgium, Denmark, Finland, France, Germany, Greece, Hungary, Ireland, Italy, Lithuania, the 
Netherlands, Portugal, Spain, Sweden and the UK) and two non-EU countries (Norway and Switzerland). These 18 countries were selected based on the availability of air pollution exposure data and the percentage of grid cells with complete air pollution and population data $(\sim 100 \%)$. From the $28 \mathrm{EU}$ countries, we excluded the following 12 countries, mainly due to the unavailability of air pollution exposure data: Bulgaria, Cyprus, Croatia, Czech Republic, Estonia, Latvia, Luxemburg, Malta, Poland, Romania, Slovakia and Slovenia. Overall, we included 63442419 children in our analyses.

The years of analysis were 2010 for the air pollution exposure data [23], and 2011 and 2012 for the population data and children's proportions data, respectively. Joining the census population and air pollution exposure data, and all analyses, was undertaken at the $1 \mathrm{~km} \times 1 \mathrm{~km}$ grid cell scale. The $1 \mathrm{~km} \times 1 \mathrm{~km}$ grid cell scale was the finest scale at which we found population data for the 18 countries. Overall, the data presented give a good spatial representation of Northern, Central and Southern Europe, but not Eastern Europe, due to the unavailability of air pollution exposure data from our models in that region [23]. This is a key limitation of this analysis as air pollution concentrations are known to be high in Eastern Europe.

The supplementary material includes a full description of the methods and the datasets underlying our analyses. Next, we only briefly describe the various steps.

\section{Census data}

The total population count at the $1 \mathrm{~km} \times 1 \mathrm{~km}$ grid cell unit was extracted from the GEOSTAT 2011 population grid database version 2.0.1 (http://ec.europa.eu/eurostat/web/gisco/geodata/reference-data/ population-distribution-demography/geostat\#geostat11). The GEOSTAT database did not specifically include childhood population counts. To calculate the childhood population count in each grid, which was our population of interest, the percentage of individuals aged 1-14 years old was extracted from the NUTS 3 dataset version 2010 (http://ec.europa.eu/eurostat/web/gisco/geodata/reference-data/administrative-unitsstatistical-units) at the regional scale, which are the smallest available regions for statistical purposes. We multiplied the percentage of individuals aged 1-14 years old from each region by the total population count, as extracted from the GEOSTAT population grid database, and calculated the childhood population count at the $1 \mathrm{~km} \times 1 \mathrm{~km}$ grid cell scale. The older childhood group (>14-18 years old) was mixed with adults (15-29 years old) and, as such, we performed our analysis exclusively for children aged 1-14 years old. We stratified our analysis by age, and present results for young children aged 1-4 years old and children aged 5-14 years old, as shown in the supplementary material.

\section{Exposure assessment model and data}

Childhood exposures to $\mathrm{NO}_{2}, \mathrm{PM}_{2.5}$ and $\mathrm{BC}$ were assessed at the $1 \mathrm{~km} \times 1 \mathrm{~km}$ grid cell scale using a validated hybrid LUR model, which is briefly described next, and is fully described in the supplementary material and in DE Hoogh et al. [23].

LUR modelling is an empirical air pollution modelling technique that uses predictor variables such as land-use, geographic, road and traffic characteristics to explain spatial variations of measured air pollution concentrations at multiple sites across the study area [24]. The set of LUR models we use comes from work reported in DE Hoogh et al. [23], where the authors modelled $\mathrm{NO}_{2}, \mathrm{PM}_{2.5}$ and $\mathrm{BC} 2010$ annual mean exposures at the $100 \mathrm{~m} \times 100 \mathrm{~m}$ grid cell scale, incorporating chemical transport model estimates $\left(\mathrm{NO}_{2}, \mathrm{PM}_{2.5}\right.$ and $\left.\mathrm{BC}\right)$ and satellite-derived data $\left(\mathrm{PM}_{2.5}\right.$ and $\left.\mathrm{BC}\right)$ together with fine-scale local predictors in a geostatistical framework, allowing us to refine the spatial scale from the otherwise coarse chemical transport model and satellite data $(\sim 10 \mathrm{~km} \times 10 \mathrm{~km})$. We used these LUR models to estimate exposures in this study area due to the availability of the models, their harmonisation across all included countries and their refinement in the most recent work reported in DE Hoogh et al. [23]. For $\mathrm{NO}_{2}$, the final model adopted had an adjusted $\mathrm{R}^{2}=0.59$, with a holdout validation $\mathrm{R}^{2}=0.58$. For $\mathrm{PM}_{2.5}$, the final model adopted had an adjusted $\mathrm{R}^{2}=0.72$, with a holdout validation $\mathrm{R}^{2}=0.66$. For $\mathrm{BC}$, the final model adopted had an adjusted $\mathrm{R}^{2}=0.54$, with a holdout validation $\mathrm{R}^{2}=0.51$. In addition, for $\mathrm{PM}_{2.5}$ and $\mathrm{NO}_{2}$, the authors performed an independent validation using monitoring sites not used in model development, which explained 0.65 and 0.49 of spatial variation in the measured concentrations, respectively [23].

\section{Matching of census and exposure data}

To match the childhood population data with the exposure estimates, the $\mathrm{NO}_{2}, \mathrm{PM}_{2.5}$ and $\mathrm{BC}$ exposure estimates from the LUR model (as described in the previous subsection) were averaged up from the $100 \mathrm{~m} \times 100 \mathrm{~m}$ grid cell scale to the $1 \mathrm{~km} \times 1 \mathrm{~km}$ grid cell scale, as this was the finest scale at which census population data were available. The average exposure estimate was then assigned to all children who lived within that $1 \mathrm{~km} \times 1 \mathrm{~km}$ grid cell. There were $15403861 \mathrm{~km} \times 1 \mathrm{~km}$ grid cells across the 18 included 
countries that had complete data and that we included in our analysis. The exposure and population characteristics in these $1 \mathrm{~km} \times 1 \mathrm{~km}$ grid cells are shown in supplementary table S1.

\section{Burden of disease assessment}

We followed standard procedures to assess the childhood asthma burden of disease in association with the three pollutants $\left(\mathrm{NO}_{2}, \mathrm{PM}_{2.5}\right.$ and $\left.\mathrm{BC}[18,25]\right)$ by: defining the exposure measures (as described earlier); defining the baseline incidence rate of asthma among the exposed children; selecting exposure-response functions to quantify the association between the exposures and the development of childhood asthma between birth and 18 years old; and combining exposure data with population data and scaled exposureresponse functions to quantify the attributable burden of incident childhood asthma cases.

\section{Baseline childhood asthma incidence rates}

The incidence rates of asthma in children (newly diagnosed cases) aged 1-4 and 5-14 years old were extracted from the Global Burden of Disease (GBD) study database (supplementary table S2) [26]. Incidence rates were extracted at the country level for 2016, which, at the time of this analysis, was the latest and theoretically the best assessment as more input data became available in recent years. The GBD data uses public and official health data records reported from health surveys and clinical records. Between 2010 (the year of the air pollution exposure assessment) and 2016, the average childhood asthma incidence rate across the 18 included countries decreased by $2 \%$ (GBD Collaborative Network; http://ghdx.healthdata. org/gbd-results-tool). Incident cases in the age group 1-14 years old for the different countries were estimated using the GBD 2016 data, by combining incident cases in the age groups 1-4 and 5-14 years old, which were directly available through the GBD datasets. We used the age-specific incidence rates in the age groups 1-4 and 5-14 years old, and also stratified our analysis in these two groups. We report the age-specific results in the supplementary material.

\section{Exposure-response functions}

Exposure-response functions for the association between the exposures to $\mathrm{NO}_{2}, \mathrm{PM}_{2.5}$ and $\mathrm{BC}$ and the subsequent development of childhood asthma from birth to 18 years old were extracted from random effects meta-analyses reported in KHREIs et al. [6]. The $\mathrm{NO}_{2}$ exposure-response function was based on 20 studies and equalled OR 1.05 (95\% CI 1.02-1.07) per exposure to $4 \mu \mathrm{g} \cdot \mathrm{m}^{-3}$. The $\mathrm{PM}_{2.5}$ exposure-response function was based on 10 studies and equalled OR 1.03 (95\% CI 1.01-1.05) per exposure to $1 \mu \mathrm{g} \cdot \mathrm{m}^{-3}$ $\mathrm{PM}_{2.5}$. The $\mathrm{BC}$ exposure-response function was based on eight studies and equalled OR 1.08 (95\% CI 1.03-1.14) per exposure to $0.5 \times 10^{-5} \mathrm{~m}^{-1} \mathrm{BC}$. Detailed information on the derivation of these exposureresponse functions, the underlying studies and asthma definitions used can be found in the original paper [6]. However, a key point worth emphasising is that studies included in this meta-analyses did not adjust for co-pollutants. As such, the numbers of incident asthma cases attributable to $\mathrm{NO}_{2}, \mathrm{PM}_{2.5}$ and $\mathrm{BC}$ should not be added up, but instead viewed as independent estimates of the potential impact of outdoor air pollution.

\section{Estimation of the impacts of exposure reduction scenarios}

We assessed the impacts of two plausible exposure reduction scenarios on the burden of incident childhood asthma. 1) Where in exceedance, the reduction of air pollution levels to comply with the World Health Organization (WHO) air quality guideline values [27]. This scenario was applicable to $\mathrm{NO}_{2}$ and $\mathrm{PM}_{2.5}$ only, as $\mathrm{BC}$ has no guideline value. 2) Where in exceedance, the reduction of air pollution levels to meet the minimum air pollution levels recorded in any of the 41 studies synthesised in the underlying systematic review from which we sourced our exposure-response functions [6]. Further details on the exact air pollution levels in both scenarios can be found in the supplementary material. The number of preventable incident childhood asthma cases that may be attributable to these scenarios was estimated. These estimates are only indicative as there is no evidence that asthma risk does not increase under these "thresholds" $[6,28]$ and policy efforts should aim at reducing air pollution as much as possible.

\section{Estimation of population attributable fraction and attributable number of cases}

Using the exposure-response functions described earlier, the risk estimates for asthma development in association with the three pollutants were scaled to the difference in exposure level between the two counterfactual scenarios and the reference scenario (current exposures as estimated from the LUR model). Each analysis was undertaken for each pollutant and scenario separately and at the $1 \mathrm{~km} \times 1 \mathrm{~km}$ grid cell scale. To scale the risk estimate from the exposure-response function concentration unit to the exposure difference between the reference and the two counterfactual scenarios, standard methods, as described in the supplementary material, were used [29]. 
The population attributable fraction (PAF) was then calculated, also for each $1 \mathrm{~km} \times 1 \mathrm{~km}$ grid cell, pollutant and scenario. PAF defines the proportional reduction in morbidity that would occur if the specific exposure, to outdoor air pollution in this case, was reduced to the counterfactual exposure scenario(s). Finally, the number of incident childhood asthma cases attributable to the excess exposure compared with the counterfactual exposure scenarios was calculated, separately for each cell, pollutant and scenario. All calculations are shown in full in the supplementary material.

\section{Results}

Figure 1 shows the spatial distribution of $\mathrm{NO}_{2}, \mathrm{PM}_{2.5}$ and $\mathrm{BC}$ across the 18 included countries. As shown in supplementary table $\mathrm{S} 1$, for the $1 \mathrm{~km} \times 1 \mathrm{~km}$ grid cells, $\mathrm{NO}_{2}$ ranged from 1.4 to $70.0 \mu \mathrm{g} \cdot \mathrm{m}^{-3}$, with an estimated mean of $11.8 \mu \mathrm{g} \cdot \mathrm{m}^{-3}$. $\mathrm{PM}_{2.5}$ ranged from 2.0 to $41.1 \mu \mathrm{g} \cdot \mathrm{m}^{-3}$, with an estimated mean of $11.6 \mu \mathrm{g} \cdot \mathrm{m}^{-3}$. BC ranged from 0.003 to $3.7 \times 10^{-5} \mathrm{~m}^{-1}$, with an estimated mean of $1.0 \times 10^{-5} \mathrm{~m}^{-1}$. The correlation between the three pollutants was moderate to high and ranged from 0.67 (between $\mathrm{NO}_{2}$ and $\mathrm{BC}$ ) to 0.81 (between $\mathrm{PM}_{2.5}$ and $\mathrm{BC}$ ). The summary statistics for exposures in each of the 18 included countries are shown in supplementary table S3.

Table 1 shows the burden of disease estimates in association with the first exposure reduction scenario: the reduction of air pollution levels to comply with the WHO air quality guideline values, when in exceedance. Overall, compliance with the $\mathrm{NO}_{2}$ WHO annual guideline value was estimated to prevent 2434 (95\% CI 1020-3307) new cases of childhood asthma a year, or $0.4 \%$ of all annual cases of childhood asthma. Compliance with the $\mathrm{PM}_{2.5}$ WHO annual guideline value was estimated to prevent 66567 (95\% CI 32213-108617) new cases of childhood asthma a year, or $11 \%$ of all annual cases of childhood asthma.

a)
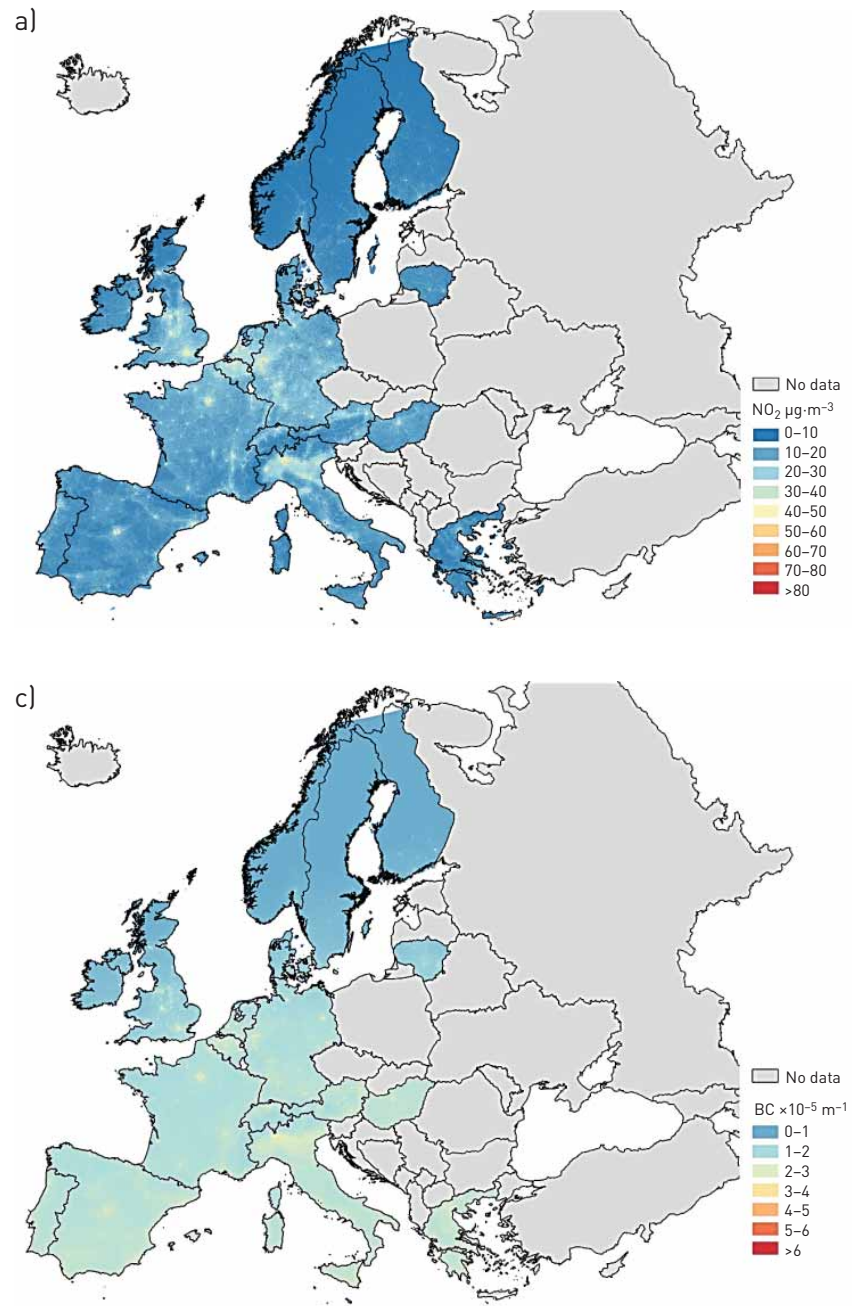

b)

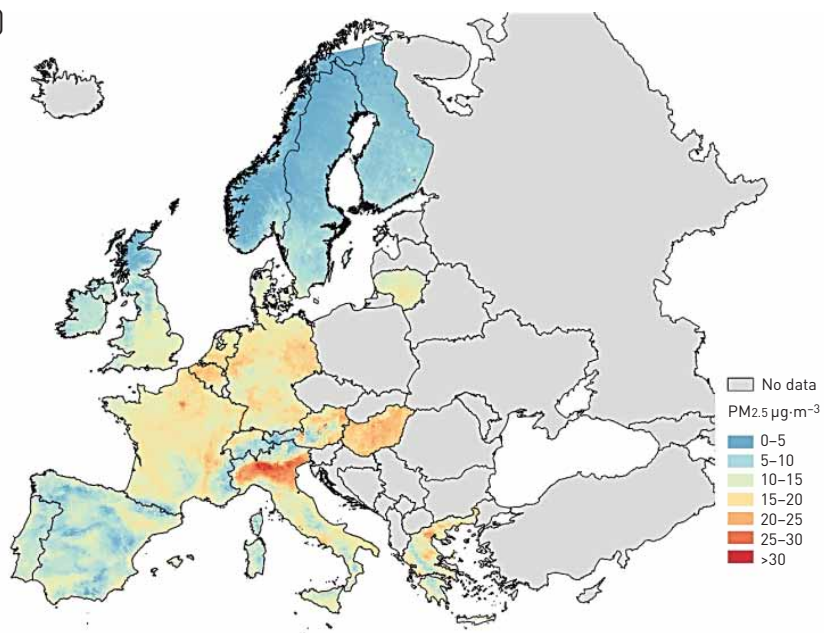

FIGURE 1 Nitrogen dioxide $\left(\mathrm{NO}_{2}\right)$, particulate matter $\leqslant 2.5 \mu \mathrm{m}$ in diameter $\left(\mathrm{PM}_{2.5}\right)$ and black carbon (BC) levels in the study area as estimated from the original $100 \mathrm{~m} \times 100 \mathrm{~m}$ grid resolution. 
TABLE 1 Burden of disease results with the World Health Organization (WHO) air quality guidelines scenario: children $1-14$ years old

\begin{tabular}{|c|c|c|c|c|c|}
\hline \multirow[t]{2}{*}{ Country } & \multirow{2}{*}{$\begin{array}{l}\text { Childhood population } \\
\text { assessed } \mathrm{n}\end{array}$} & \multicolumn{2}{|c|}{$\mathrm{NO}_{2}$ WHO guideline value ${ }^{\#}$} & \multicolumn{2}{|c|}{$\mathrm{PM}_{2.5}$ WHO guideline value ๆ $^{\text {? }}$} \\
\hline & & $\begin{array}{l}\text { Total cases attributable } \\
\text { to exposure scenario } \%\end{array}$ & $\begin{array}{l}\text { Attributable expected } \\
\text { cases } \mathrm{n}(95 \% \mathrm{CI})\end{array}$ & $\begin{array}{l}\text { Total cases attributable } \\
\text { to exposure scenario \% }\end{array}$ & $\begin{array}{l}\text { Attributable expected } \\
\text { cases n }(95 \% \mathrm{Cl})\end{array}$ \\
\hline Belgium & 1788001 & 0.72 & $99(41-135)$ & 21.31 & 2924 (1067-4468) \\
\hline Denmark & 899709 & 0.01 & $0.47(0.19-0.65)$ & 5.81 & 537 (186-862) \\
\hline Finland & 840626 & 0.00 & $0(0-0)$ & 0.19 & $14(5-23)$ \\
\hline Greece & 1413106 & 0.81 & 90 (37-123) & 18.32 & 2036 (739-3130) \\
\hline Hungary & 1319551 & 0.00 & $0(0-0)$ & 24.61 & $2801(1034-4234)$ \\
\hline Ireland & 966048 & 0.00 & $0(0-0)$ & 0.46 & $50(17-82)$ \\
\hline Italy & 7791095 & 0.56 & $295(124-400)$ & 20.84 & $11001(4119-16471)$ \\
\hline Lithuania & 390930 & 0.00 & $0(0-0)$ & 10.79 & $426(150-673)$ \\
\hline Netherlands & 2625237 & 0.42 & 80 (33-109) & 18.01 & 3456 (1245-5347) \\
\hline Switzerland & 1172805 & 0.02 & $2(1-3)$ & 14.17 & 1523 (544-2374) \\
\hline UK & 10905872 & 0.27 & 408 (170-558) & 6.81 & 10409 (3624-16 633) \\
\hline Total & 63442419 & 0.42 & 2434 (1020-3307) & 11.49 & 66567 (32213-108617) \\
\hline
\end{tabular}

$\mathrm{NO}_{2}$ : nitrogen dioxide; $\mathrm{PM}_{2.5}$ : particulate matter $\leqslant 2.5 \mu \mathrm{m}$ in diameter. ${ }^{\#}: \mathrm{NO}_{2}$ reduced to $40 \mu \mathrm{g} \cdot \mathrm{m}^{-3}$ (annual average), where in exceedance; ก: $\mathrm{PM}_{2.5}$ reduced to $10 \mu \mathrm{g} \cdot \mathrm{m}^{-3}$ (annual average), where in exceedance.

The variation in the burden of disease estimates between the countries was also notable, as shown in table 1 . Depending on the percentage of attributable cases, Spain was estimated to benefit the most from complying with the WHO $\mathrm{NO}_{2}$ air quality guideline value, potentially preventing $1.6 \%$ of all its annual cases of childhood asthma. Finland, Hungary, Ireland, Lithuania and Norway had no grid cells exceeding the WHO $\mathrm{NO}_{2}$ air quality guideline. In terms of compliance with the $\mathrm{PM}_{2.5}$ WHO air quality guideline value, Hungary was estimated to benefit the most from complying, potentially preventing $24 \%$ of all its annual cases of childhood asthma, while Finland was estimated to benefit the least, potentially preventing $0.2 \%$ of all its annual cases.

Stratifying the results by age group for young children aged 1-4 years old and children aged 5-14 years old yielded similar results, as shown in supplementary tables S4 and S5.

For young children aged $1-4$ years old $(n=17528813)$, compliance with the $\mathrm{NO}_{2}$ WHO annual guideline value was estimated to prevent 1288 (95\% CI 540-1750) new cases of childhood asthma a year, or $0.4 \%$ of all annual cases of childhood asthma, while compliance with the $\mathrm{PM}_{2.5}$ WHO annual guideline value was estimated to prevent 36471 (95\% CI 13 147-56465) new cases of childhood asthma a year, or almost $12 \%$ of all annual cases of childhood asthma. For children aged 5-14 years old ( $\mathrm{n}=45913606)$, compliance with the $\mathrm{NO}_{2}$ WHO annual guideline value was estimated to prevent 1146 (95\% CI 480-1557) new cases of childhood asthma a year, or $0.4 \%$ of all annual cases of childhood asthma, while compliance with the $\mathrm{PM}_{2.5}$ WHO annual guideline value was estimated to prevent 30095 (95\% CI 19056-52 152) new cases of childhood asthma a year, or $11 \%$ of all annual cases of childhood asthma. The variation in the burden of disease estimates between the countries was similar to the overall analysis.

Table 2 shows the burden of disease estimates in association with the second exposure reduction scenario: meeting the minimum air pollution levels recorded in any of the 41 studies synthesised in the most recent systematic review on TRAP and risk of incident childhood asthma [6]. Overall, meeting the minimum air pollution level for $\mathrm{NO}_{2}$ was estimated to prevent 135257 (95\% CI $60187-177093$ ) new cases of childhood asthma a year, or $23 \%$ of all annual cases of childhood asthma. Meeting the minimum air pollution level for $\mathrm{PM}_{2.5}$ was estimated to prevent 191883 (95\% CI 74198-278802) new cases of childhood asthma a year, or $33 \%$ of all annual cases of childhood asthma. Meeting the minimum air pollution level for BC was estimated to prevent 89191 (95\% CI 36461-141764) new cases of childhood asthma a year, or 15\% of all annual cases of childhood asthma. The variations in the burden of disease estimates between the countries was also notable, as shown in table 2, and depended on the pollutant selected in the analysis. For example, 
TABLE 2 Burden of disease results with the minimum air pollution levels scenario: children 1-14 years old

\begin{tabular}{|c|c|c|c|c|c|c|c|}
\hline \multirow[t]{2}{*}{ Country } & \multirow{2}{*}{$\begin{array}{l}\text { Childhood } \\
\text { population } \\
\text { assessed } n\end{array}$} & \multicolumn{2}{|r|}{$\mathrm{NO}_{2}{ }^{\#}$} & \multicolumn{2}{|r|}{$\mathrm{PM}_{2.5}{ }^{\pi}$} & \multicolumn{2}{|r|}{$\mathrm{BC}^{+}$} \\
\hline & & $\begin{array}{c}\text { Total cases } \\
\text { attributable } \\
\text { to exposure } \\
\text { scenario } \%\end{array}$ & $\begin{array}{l}\text { Attributable expected } \\
\text { cases } \mathrm{n}(95 \% \mathrm{CI})\end{array}$ & $\begin{array}{l}\text { Total cases } \\
\text { attributable } \\
\text { to exposure } \\
\text { scenario } \%\end{array}$ & $\begin{array}{l}\text { Attributable expected } \\
\text { cases } \mathrm{n}(95 \% \mathrm{CI})\end{array}$ & $\begin{array}{l}\text { Total cases } \\
\text { attributable } \\
\text { to exposure } \\
\text { scenario } \%\end{array}$ & $\begin{array}{l}\text { Attributable expected } \\
\text { cases } \mathrm{n}(95 \% \mathrm{CI})\end{array}$ \\
\hline Austria & 1165734 & 23 & 2159 (955-2837) & 39 & 3755 (1490-5333) & 19 & 1824 (751-2876) \\
\hline Belgium & 1788001 & 29 & 3931 (1770-5108) & 41 & 5591 (2220-7928) & 19 & 2646 (1088-4178) \\
\hline France & 11234118 & 23 & 22879 (10 179-29966) & 37 & 37638 (14754-54009) & 18 & 17921 (7361-28341) \\
\hline Germany & 10459150 & 24 & 16897 (7474-22 199) & 37 & $26287(10256-37854)$ & 16 & 11231 (4561-17975) \\
\hline Greece & 1413106 & 22 & 2409 (1082-3138) & 38 & $4269(1680-6101)$ & 23 & 2553 (1067-3963) \\
\hline Hungary & 1319551 & 18 & 2021 (876-2688) & 43 & 4920 (1977-6907) & 18 & 2019 (824-3212) \\
\hline Ireland & 966048 & 14 & $1500(645-2006)$ & 22 & $2373(866-3627)$ & 5 & 558 (221-917) \\
\hline Italy & 7791095 & 24 & 12518 (5579-16376) & 40 & 21289 (8538-30003) & 20 & 10820 (4470-16996) \\
\hline Spain & 6579656 & 25 & $11356(5116-14765)$ & 30 & 13768 (5220-20339) & 21 & $9721(4031-15211)$ \\
\hline Sweden & 1628914 & 16 & $3035(1314-4041)$ & 20 & 3908 (1425-5982) & 5 & 892 (352-1472) \\
\hline Switzerland & 1172805 & 22 & $2317(1018-3056)$ & 35 & 3783 (1466-5479) & 17 & $1855(757-2951)$ \\
\hline UK & 10905872 & 26 & 40088 (17927-52314) & 29 & 44895 (16939-66 585) & 13 & 19139 (7721-30855) \\
\hline Total & 63442419 & 23 & 135257 (60 187-177093) & 33 & 191883 (74 198-278802) & 15 & $89191(36461-141764)$ \\
\hline
\end{tabular}

$\mathrm{NO}_{2}$ : nitrogen dioxide; $\mathrm{PM}_{2.5}$ : particulate matter $\leqslant 2.5 \mu \mathrm{m}$ in diameter; $\mathrm{BC}$ : black carbon. ${ }^{\#}$ : $\mathrm{NO}_{2}$ reduced to $1.5 \mu \mathrm{g} \cdot \mathrm{m}^{-3}$ (annual average) as recorded in OftedAL et al. [30], where in exceedance; ${ }^{9}$ : $\mathrm{PM}_{2.5}$ reduced to $0.4 \mu \mathrm{g} \cdot \mathrm{m}^{-3}$ (annual average) as recorded in FUERTES et al. [31], where in exceedance; ${ }^{+}$: BC reduced to $0.4 \times 10^{-5} \mathrm{~m}^{-1}$ (annual average) as recorded in GEHRING et al. [32], where in exceedance.

Belgium and the Netherlands are the countries that would benefit the most from the absolute reduction of $\mathrm{NO}_{2}$ levels (29\% of all annual cases of childhood asthma may be prevented), while for $\mathrm{PM}_{2.5}$ and $\mathrm{BC}$, respectively, the countries that would benefit the most were Hungary (43\%) and Greece (23\%).

Stratifying the results by age group for young children aged 1-4 years old and children aged 5-14 years old yielded similar results, as shown in supplementary tables S6 and S7.

For young children aged $1-4$ years old $(n=17528813)$, meeting the minimum air pollution level for $\mathrm{NO}_{2}$ was estimated to prevent 72497 (95\% CI 32265-94910) new cases of childhood asthma a year, or 23\% of all annual cases of childhood asthma, while meeting the minimum air pollution level for $\mathrm{PM}_{2.5}$ and $\mathrm{BC}$ was estimated to prevent 101792 (95\% CI 39307-148074) new cases of childhood asthma a year, or 33\% of all annual cases of childhood asthma, and 47139 (95\% CI 19262-74962) new cases of childhood asthma a year, or $15 \%$ of all annual cases of childhood asthma, respectively. The percentage of attributable cases was also similar in the older age group. The variation in the burden of disease estimates between the countries was similar to the overall analysis.

\section{Discussion}

Summary and comparison with other studies

In this study, we estimated that up to $33 \%$ of all childhood asthma cases could be attributed to air pollution exposures $\left(\mathrm{PM}_{2.5}\right)$ in 18 European countries and 63442419 children aged 1-14 years old. These cases are potentially preventable. We also found that the attributable percentage of cases varied according to the pollutant studied ( $23 \%$ for $\mathrm{NO}_{2}$ and $15 \%$ for $\mathrm{BC}$ ) and the exposure reduction scenario investigated. The attributable percentage of cases was not sensitive to the use of age-specific asthma incidence rates as shown in our stratified analysis for the age groups 1-4 and 5-14 years old.

This study significantly expands on the coverage of previous similar burden of disease assessments and offers wider estimates. It also highlights the variations in air pollution exposures and associated burden of disease across 18 European countries using harmonised LUR models. Our analysis suggested that compliance with the $\mathrm{NO}_{2}$ WHO air quality guideline value could prevent 2434 (or $0.4 \%$ of all) childhood asthma cases from developing per year. Compliance with the $\mathrm{PM}_{2.5}$ WHO air quality guideline value had a larger impact, with an estimated 66567 (or 11\%) preventable incident childhood asthma cases per year. 
However, we believe that the current WHO air quality guideline values are outdated and require update and lowering, which is currently underway. Using lower thresholds in the future may therefore result in an even larger burden.

Furthermore, while we believe that the WHO air quality guideline values for both pollutants $\left(\mathrm{NO}_{2}\right.$ and $\mathrm{PM}_{2.5}$ ) offer useful policy references and compliance scenarios, there is in fact no evidence that the risk of developing childhood asthma does not increase under these "thresholds" [6, 28]. Instead, policy efforts should aim at reducing air pollution levels as much as possible. As such, we also tested the impact of reducing the air pollution levels to meet the minimum levels recorded in any of the 41 studies synthesised in the most recent systematic review on TRAP and the risk of incident childhood asthma, from which we sourced our exposure-response functions [6]. The analysis of this scenario suggested that meeting minimum levels as recorded in the literature for $\mathrm{NO}_{2}, \mathrm{PM}_{2.5}$ and $\mathrm{BC}$ could prevent, respectively, 135257 (or 23\%), 191883 (or 33\%) and 89191 (or 15\% of all) childhood asthma cases from developing per year.

These estimates are in line with two previous Bradford studies which found that the percentage of annual incident childhood asthma attributable to all $\mathrm{NO}_{2}$ (i.e. exposure elimination scenario) was $22 \%$ [20], while the percentage of annual incident childhood asthma attributable to eliminating all $\mathrm{PM}_{2.5}$ and $\mathrm{BC}$ was $27 \%$ and $15 \%$, respectively [21]. The only European-focused analysis previously published on this topic estimated that exposure to roads with high vehicle traffic, a proxy for near-road TRAP, accounted for $14 \%$ of all asthma prevalent cases [17]. As such, our study's burden of disease estimates are higher than the only previous European analysis, which may be explained by the different exposure models we used and the fact that our LUR model's air pollution estimates incorporate air pollution from sources beyond traffic. Interestingly, however, the BC burden of disease estimates in this study (15\%) were very comparable to the burden of disease estimates in association with proximity to roads with high traffic in the previous European analysis (14\%) [17]. BC is indeed a relatively specific marker for traffic in urban Europe [33], especially truck traffic [34], and these similar estimates might reflect traffic as a common source of air pollution and the attributable burden. Furthermore, during the write-up of this article, two more recent burden of disease analyses were also published. The first, which was conducted for the contiguous USA across 48 states and the District of Columbia, attributed 18\% of all childhood asthma cases in 2010 to $\mathrm{NO}_{2}$, a fairly specific marker of TRAP [22]. The second, which was conducted for 194 countries across the world, attributed $13 \%$ of global incidence to $\mathrm{NO}_{2}$, while the European analysis subset reported in the same article estimated that $17 \%$ of the burden in Western Europe, 14\% in Central Europe and 17\% in Eastern Europe was attributable to $\mathrm{NO}_{2}$ [35]. All of the above estimates, which have mostly emerged in the past 2 years, are similar and strengthen the case from different research teams that air pollution is contributing substantially to the burden of childhood asthma.

\section{Strengths and limitations}

Thus far, our study offers one of the widest coverages of the burden of incident childhood asthma attributable to outdoor air pollution, with a specific focus on Europe. It is the first study to investigate the childhood asthma burden of disease in association with three common air pollutants that have been associated with increased risk of childhood asthma onset, given that the most relevant pollutant to be included in the analysis remains unknown. Our analysis allows for comparison across 18 European countries, using harmonised air quality assessment models. We also used a validated set of LUR models to assess exposure to three ubiquitous air pollutants $\left(\mathrm{NO}_{2}, \mathrm{PM}_{2.5}\right.$ and $\left.\mathrm{BC}\right)$ and showed that the burden of disease estimates vary across the different pollutants, but are comparable with previous similar studies. We used pooled exposure-response functions of continuous pollutant exposures [6], as opposed to an exposure-response function from a single study relying on a traffic proximity exposure measure [36], as has been done in the past European assessment [17]. In the absence of location-specific and population-specific exposure-response functions, we believe that using a pooled exposure-response function is more appropriate when extrapolating risk estimates to different locations and diverse populations.

Although individual studies included in the pooled exposure-response function underlying our analysis adjusted for major confounders that can also increase the risk of childhood asthma onset (e.g. socioeconomic status, smoking and parental atopy) [6], there were no specific exposure-response functions based on these variables (e.g. an exposure-response function for low versus high median household income) and, as such, we could not account for this in our analysis. This is a persistent limitation in burden of disease studies that generally rely on published epidemiological literature to source appropriate exposure-response functions. So far, the assessment of exposure-response functions has been done in an aggregate manner that does not consider subpopulations or stratify by potential effect modifiers, such as socioeconomic factors, and this is especially true in the case of childhood asthma onset in association with 
air pollution [6]. The pooled exposure-response functions we used were pollutant specific and, as such, were better suited to capture the impact of the spatial variability of pollutants, allowing us to investigate the different impacts attributable to the different pollutants. The most suitable pollutant to be used in future burden of disease exercises, however, is unclear, may depend on the source of air pollution of interest, and should be considered in the context of the wider literature and toxicological evidence. Finally, the burden of disease estimates we present in this article offer a new basis for the monetisation of health impacts associated with outdoor air pollution in Europe.

A key limitation of this analysis is the use of exposure estimates at the $1 \mathrm{~km} \times 1 \mathrm{~km}$ grid cell scale. Unfortunately, the total population counts were only available at the $1 \mathrm{~km} \times 1 \mathrm{~km}$ grid cell scale. As such, we conducted our exposure assessment at the same spatial resolution. Currently, the impact of averaging exposures at this coarser geographical scale on the burden of disease estimates is unknown and warrants further investigation. However, in the context of the literature, this analysis advances previous efforts and better accounts for the spatial distribution of air pollution, across a range of three ubiquitous air pollutants [17], which have not been systematically included in previous burden of disease assessments. We also only assigned exposures at the $1 \mathrm{~km} \times 1 \mathrm{~km}$ grid cell scale in which residential locations/addresses fell. There is well-established spatiotemporal variability in air pollution exposures at the indoor, outdoor and personal levels [37, 38], including for children who spend several hours at schools where the exposure can differ from their residential addresses. However, the currently available data did not allow us to consider activity patterns in the assessment of children's exposure to the three pollutants and the attributable health impacts, partly due to the large sample size of this analysis (more than 63 million children). This is a common limitation in large burden of disease assessments. Despite not being able to account for children's activity patterns in our analysis, the pooled exposure-response functions we used were predominantly based on residential locations and long-term/annual average air pollution concentrations [6], and, as such, support the use of the grid cell scale in which residential locations fell in this instance. Furthermore, there is evidence in the literature that the associations between new-onset asthma and modelled air pollution exposures are slightly stronger at home than at school, although strongest when both home and school exposures are combined [39]. Our analysis also generally gives a good spatial representation of Northern, Central and Southern Europe, but not Eastern Europe. Eastern Europe was not included in the analyses due to the unavailability of exposure data for the three pollutants in that region. This is a key data gap that future research should aim to fill, especially since air pollution concentrations are known to be high in Eastern Europe.

Other limitations relate to uncertainty in the underlying asthma incidence rates, the exposure-response functions and the assumption that outdoor air pollution is causally associated with the development of childhood asthma.

First, asthma is a complex and heterogeneous disease with a challenging diagnosis and challenges in the data collection and harmonisation due to the use of different tools (health surveys and records) between, and within, countries, and even among local health structures. The variations of asthma incidence rates across Europe cannot be solely explained by variations in air pollution levels. This could be due to the differences in country asthma incidence rates, which may be strongly influenced by the structure of national health services and diagnosis practices that are known to vary by country. Also, it is well established that the risk of asthma incidence is impacted by a wide variety of factors beyond air pollution, which have been generally associated with larger risk estimates, but which we could not directly account for in our burden of disease. These factors include a family history of asthma as there is a strong familial clustering of the disease, a family history of allergic conditions such as atopic dermatitis, rhinitis and food allergy, early-life upper and lower respiratory tract infections, exposures to indoor allergens, and others. Variations in these factors may better explain variations in incidence rates across Europe. Incidence rates are also influenced by other factors, including the structure of national health services and heterogeneities among local health structures. This study provides a national-level assessment, using national incidence rates from the GBD project to each unit of analysis ( $1 \mathrm{~km} \times 1 \mathrm{~km}$ grid cell scale). For this reason, we were not able to provide the expected subnational geographical variability in asthma incidence rates that could be expected from heterogeneity in national, regional and local health structures. Finally, the three pollutants we used in our analysis might be surrogates for the true putative agents in the air pollution mixture, which remain unknown and unmeasured, and may better explain variations in incidence.

Asthma diagnosis also differs by age. To address this latter point, we re-ran all our analyses using age-specific asthma incidence rates, stratifying the results in two age groups indexed in the GBD datasets: 1-4 and 5-14 years old. The age-specific analysis yielded similar results to the overall aggregate analysis.

Second, there is statistical uncertainty associated with the risk estimates that were sourced from the pooled exposure-response functions. However, we have provided a range of this uncertainty by using the lower 
and upper 95\% confidence intervals and estimating a range for the burden of disease associated with each central estimate. Furthermore, the individual studies included in the underlying meta-analyses did not adjust for co-pollutants. Therefore, the incident asthma cases attributable to $\mathrm{NO}_{2}, \mathrm{PM}_{2.5}$ and $\mathrm{BC}$ should not be added up, but instead viewed as independent estimates of the potential impact of outdoor air pollution on childhood asthma burden. Indeed, the correlation between the three pollutants we investigated was moderate to high, ranging from 0.67 (between $\mathrm{NO}_{2}$ and $\mathrm{BC}$ ) to 0.81 (between $\mathrm{PM}_{2.5}$ and $\mathrm{BC}$ ).

Another important question that remains open is what are the putative agents in the air pollution mixture? Our analysis is based on the underlying assumption that outdoor air pollution is associated with childhood asthma onset. Although we believe that there is sufficient evidence now to support an association between TRAP exposure and the development of childhood asthma, the evidence is less clear for generic outdoor air pollution (i.e. air pollution not associated with traffic sources) [6] and is better established in relation to exposures during early life, specifically the first 3 years of life [6]. As such, the smaller burden of disease estimates in association with $\mathrm{NO}_{2}$ and $\mathrm{BC}$, despite potentially not being the putative agents, could be a better representation of the true burden, as these pollutants are more specific markers for traffic than $\mathrm{PM}_{2.5}$ [40-42]. This, however, is an open question. Whether pollutants act in single or multiple causal pathways leading to the development of asthma is unknown. Although the assumption underlying our analyses and the exposure-response functions we used is that childhood and early life in particular represent the most critical exposure windows, it could be that exposures in later life also contribute to the development of asthma. Studies systematically investigating associations with multiple windows of exposures are scarce and more research to establish these associations, and how later-life exposures might impact the risk of asthma onset differently, is needed.

\section{Research and policy recommendations}

Future research can usefully develop and match population and exposure maps at a finer spatial resolution and assess the impact of averaging exposures at the $1 \mathrm{~km} \times 1 \mathrm{~km}$ scale on final burden of disease estimates. There is currently little knowledge on the impact of spatial resolution of the exposure assessment on burden of disease estimates. The potential future availability of population and underlying baseline asthma rates at a smaller geographical scale can advance current knowledge. Similarly, a more accurate representation of mobility and resulting exposure patterns is under-investigated in burden of disease assessment studies overall, likely owing to the large coverage of such analyses, which typically include hundreds of thousands to millions of individuals. The exposure assessment method we used in this study did not allow us to trace certain proportions of the burden of disease back to the air pollution sources responsible. The use of dispersion models, for example, which can specify the contribution of traffic to the overall air pollution and asthma burden, can provide further insights, but again such models have not been typically used in large burden of disease studies and they impose severe data, software and expertise demands [20]. Future work should also investigate the differential effects of air pollution exposure on childhood asthma development by different susceptibility factors, such as ethnicity, socioeconomic status, age and sex. The populations included this analysis are likely to have very different underlying susceptibility factors. Yet, these factors and the resulting differential burden cannot be considered given the current lack of subgroup-specific exposure-response functions. Future work would also benefit from exposure-response functions adjusted by other pollutants. At present, a distinction between pollutant-specific effects is not possible.

Our results suggest that compliance with the $\mathrm{NO}_{2}$ WHO air quality guideline value may prevent 2434 (or $0.4 \%$ ) childhood asthma cases from developing per year, while compliance with the $\mathrm{PM}_{2.5}$ WHO air quality guideline value may prevent 66567 (or 11\%) incident childhood asthma cases per year. There is no evidence that the risk of developing childhood asthma does not increase under these "thresholds" $[6,28]$ and policy efforts should reduce exposure levels as much as possible.

The attribution of incident asthma cases to air pollution also has substantial implications for the burden of asthma-related exacerbations. As air pollution increases the risk of developing new asthma cases, all future acute exacerbations of these cases, regardless of subsequent (immediate) causes of the exacerbations, should again be attributed to air pollution. This conceptual model has been previously followed in the literature where the burden of disease estimates attributable to air pollution were revised to account not only for asthma symptoms that are directly triggered by air pollution, but also for asthma symptoms triggered by other causes in children who developed asthma because of air pollution. The result was a significantly higher burden of disease estimate, and perhaps a more realistic picture of the societal and economic impact of air pollution $[16,43]$. These impacts are largely preventable, and there are numerous transport and land-use policy measures at the city level that can reduce the ambient levels of and exposures to outdoor air pollution [44]. 


\section{Conclusions}

We estimated that, per year, $0.4 \%$ and $11 \%$ of all incident childhood asthma cases across 18 European countries may be prevented by complying with the WHO air quality guideline values for $\mathrm{NO}_{2}$ and $\mathrm{PM}_{2.5}$, respectively. These results suggest that the current $\mathrm{NO}_{2}$ air quality guideline provides less protection than the $\mathrm{PM}_{2.5}$ guideline, in light of the most recent evidence that there is no threshold for these pollutants under which no health effects occur. Both values may require update and lowering to be better suited for protecting children's health. A much larger proportion of incident childhood asthma cases (15-33\%) could be prevented by lowering $\mathrm{NO}_{2}, \mathrm{PM}_{2.5}$ and $\mathrm{BC}$ levels to minimum levels recorded in the literature; this is a relevant issue given the lack of evidence that a safe air pollution threshold exists. Our estimates are larger than in previous documentation and underline the urgent need to reduce children's air pollution exposure across Europe. We also showed that the selection of pollutant in the burden of disease assessment makes a measurable impact on final estimates. The most suitable pollutant to be used in future burden of disease exercises, however, is unclear, may depend on the source of air pollution of most interest, and should be considered in the context of the available toxicological evidence and biological plausibility. In summary, there is an urgent need to reduce children's exposure to air pollution.

Conflict of interest: None declared.

\section{References}

1 Global Asthma Network. The Global Asthma Report 2014. www.globalasthmareport.org/2014/resources/Global_ Asthma_Report_2014.pdf Date last accessed: July 28, 2019.

2 Gasana J, Dillikar D, Mendy A, et al. Motor vehicle air pollution and asthma in children: a meta-analysis. Environ Res 2012; 117: 36-45.

3 Gaffin J, Phipatanakul W. Beta-2-adrenergic receptor methylation may influence asthma phenotype in the School Inner City Asthma Study. Receptors Clin Investig 2014; 1: e15.

4 Asher I, Pearce N. Global burden of asthma among children. Int J Tuberc Lung Dis 2014; 18: 1269-1278.

5 Gibson GJ, Loddenkemper R, Lundbäck B, et al. Respiratory health and disease in Europe: the new European Lung White Book. Eur Respir J 2013; 42: 559-563.

6 Khreis H, Kelly C, Tate J, et al. Exposure to traffic-related air pollution and risk of development of childhood asthma: a systematic review and meta-analysis. Environ Int 2017; 100: 1-31.

7 Richmond-Bryant J, Saganich C, Bukiewicz L, et al. Associations of $\mathrm{PM}_{2.5}$ and black carbon concentrations with traffic, idling, background pollution, and meteorology during school dismissals. Sci Total Environ 2009; 407: 3357-3364.

8 Anderson H, Favarato G, Atkinson R. Long-term exposure to outdoor air pollution and the prevalence of asthma: meta-analysis of multi-community prevalence studies. Air Qual Atmos Health 2013; 6: 57-68.

9 Anderson HR, Favarato G, Atkinson RW. Long-term exposure to air pollution and the incidence of asthma: meta-analysis of cohort studies. Air Qual Atmos Health 2013; 6: 47-56.

10 Rice MB, Rifas-Shiman SL, Litonjua AA, et al. Lifetime air pollution exposure and asthma in a pediatric birth cohort. J Allergy Clin Immunol 2018; 141: 1932-1934.

11 Pennington AF, Strickland MJ, Klein M, et al. Exposure to mobile source air pollution in early-life and childhood asthma incidence: the Kaiser Air Pollution and Pediatric Asthma Study. Epidemiology 2018; 29: 22-30.

12 Rancière F, Bougas N, Viola M, et al. Early exposure to traffic-related air pollution, respiratory symptoms at 4 years of age, and potential effect modification by parental allergy, stressful family events, and sex: a prospective follow-up study of the PARIS birth cohort. Environ Health Perspect 2016; 125: 737-745.

13 Tétreault L-F, Doucet M, Gamache P, et al. Childhood exposure to ambient air pollutants and the onset of asthma: an administrative cohort study in Québec. Environ Health Perspect 2016; 124: 1276-1282.

14 Esposito S, Tenconi R, Lelii M, et al. Possible molecular mechanisms linking air pollution and asthma in children. BMC Pulm Med 2014; 14: 31

15 Gowers AM, Cullinan P, Ayres JG, et al. Does outdoor air pollution induce new cases of asthma? Biological plausibility and evidence; a review. Respirology 2012; 17: 887-898.

16 Künzli N, Perez L, Lurmann F, et al. An attributable risk model for exposures assumed to cause both chronic disease and its exacerbations. Epidemiology 2008; 19: 179-185.

17 Perez L, Declercq C, Iñiguez C, et al. Chronic burden of near-roadway traffic pollution in 10 European cities (APHEKOM network). Eur Respir J 2013; 42: 594-605.

18 Perez L, Künzli N, Avol E, et al. Global goods movement and the local burden of childhood asthma in southern California. Am J Public Health 2009; 99: S622-S628.

19 Perez L, Lurmann F, Wilson J, et al. Near-roadway pollution and childhood asthma: implications for developing "win-win" compact urban development and clean vehicle strategies. Environ Health Perspect 2012; 120: 1619-1626.

20 Khreis H, de Hoogh K, Nieuwenhuijsen MJ. Full-chain health impact assessment of traffic-related air pollution and childhood asthma. Environ Int 2018; 114: 365-375.

21 Khreis H, Ramani T, de Hoogh K, et al. Traffic-related air pollution and the local burden of childhood asthma in Bradford, UK. Int J Transport Sci Technol 2019; 8: 116-128.

22 Alotaibi R, Bechle M, Marshall JD, et al. Traffic related air pollution and the burden of childhood asthma in the contiguous United States in 2000 and 2010. Environ Int 2019; 127: 858-867.

23 de Hoogh K, Chen J, Gulliver J, et al. Spatial $\mathrm{PM}_{2.5}, \mathrm{NO}_{2}, \mathrm{O}_{3}$ and $\mathrm{BC}$ models for Western Europe - evaluation of spatiotemporal stability. Environ Int 2018; 120: 81-92.

24 Wang M, Brunekreef B, Gehring U, et al. A new technique for evaluating land use regression models and their impact on health effect estimates. Epidemiology 2016; 27: 51-56.

25 World Health Organization. Quantitative assessment of environmental health impacts at population level. 2015. www.who.int/heli/tools/quantassess/en Date last accessed: January 12, 2017. 
Vos T, Abajobir AA, Abate KH, et al. Global, regional, and national incidence, prevalence, and years lived with disability for 328 diseases and injuries for 195 countries, 1990-2016: a systematic analysis for the Global Burden of Disease Study 2016. Lancet 2017; 390: 1211-1259.

27 World Health Organization. WHO air quality guidelines for particulate matter, ozone, nitrogen dioxide and sulfur dioxide. Global update 2005. Summary of risk assessment. 2006. https://apps.who.int/iris/bitstream/handle/10665/ 69477/WHO_SDE_PHE_OEH_06.02_eng.pdf Date last accessed: July 28, 2019.

28 Health Effects Institute. Traffic-related air pollution: a critical review of the literature on emissions, exposure, and health effects. Special Report 17. 2010. www.healtheffects.org/publication/traffic-related-air-pollution-critical-reviewliterature-emissions-exposure-and-health Date last accessed: July 28, 2019.

29 Rojas-Rueda D, de Nazelle A, Teixidó O, et al. Replacing car trips by increasing bike and public transport in the greater Barcelona metropolitan area: a health impact assessment study. Environ Int 2012; 49: 100-109.

30 Oftedal B, Nystad W, Brunekreef B, et al. Long-term traffic-related exposures and asthma onset in schoolchildren in Oslo, Norway. Environ Health Perspect 2009; 117: 839-844.

31 Fuertes E, Standl M, Cyrys J, et al. A longitudinal analysis of associations between traffic-related air pollution with asthma, allergies and sensitization in the GINIplus and LISAplus birth cohorts. PeerJ 2013; 1: e193.

32 Gehring U, Wijga AH, Hoek G, et al. Exposure to air pollution and development of asthma and rhinoconjunctivitis throughout childhood and adolescence: a population-based birth cohort study. Lancet Respir Med 2015; 3: 933-942.

33 Briggs NL, Long CM. Critical review of black carbon and elemental carbon source apportionment in Europe and the United States. Atmos Environ 2016; 144: 409-427.

34 Roorda-Knape MC, Janssen NA, De Hartog JJ, et al. Air pollution from traffic in city districts near major motorways. Atmos Environ 1998; 32: 1921-1930.

35 Achakulwisut P, Brauer M, Hystad P, et al. Global, national, and urban burdens of paediatric asthma incidence attributable to ambient $\mathrm{NO}_{2}$ pollution: estimates from global datasets. Lancet Planet Health 2019; 3: e166-e178.

36 McConnell R, Berhane K, Yao L, et al. Traffic, susceptibility, and childhood asthma. Environ Health Perspect 2006; 114: 766-772.

37 Park YM, Kwan M-P. Individual exposure estimates may be erroneous when spatiotemporal variability of air pollution and human mobility are ignored. Health Place 2017; 43: 85-94.

38 Nieuwenhuijsen MJ, Donaire-Gonzalez D, Rivas I, et al. Variability in and agreement between modeled and personal continuously measured black carbon levels using novel smartphone and sensor technologies. Environ Sci Technol 2015; 49: 2977-2982.

39 McConnell R, Islam T, Shankardass K, et al. Childhood incident asthma and traffic-related air pollution at home and school. Environ Health Perspect 2010; 118: 1021-1026.

40 Zhu Y, Hinds WC, Kim S, et al. Study of ultrafine particles near a major highway with heavy-duty diesel traffic. Atmos Environ 2002; 36: 4323-4335.

41 Cyrys J, Eeftens M, Heinrich J, et al. Variation of $\mathrm{NO}_{2}$ and $\mathrm{NO}_{x}$ concentrations between and within 36 European study areas: results from the ESCAPE study. Atmos Environ 2012; 62: 374-390.

42 Eeftens M, Tsai MY, Ampe C, et al. Spatial variation of $\mathrm{PM}_{2.5}, \mathrm{PM}_{10}, \mathrm{PM}_{2.5}$ absorbance and $\mathrm{PM}_{\text {coarse }}$ concentrations between and within 20 European study areas and the relationship with $\mathrm{NO}_{2}-$ results of the ESCAPE project. Atmos Environ 2012; 62: 303-317.

43 Brandt SJ, Perez L, Künzli N, et al. Costs of childhood asthma due to traffic-related pollution in two California communities. Eur Respir J 2012; 40: 363-370.

44 Khreis H, May A, Nieuwenhuijsen M. Health impacts of urban transport policy measures: a guidance note for practice. J Transport Health 2017; 6: 209-227. 